\title{
The Relationship of Perforated Appendicitis with Total and Direct Bilirubin
}

\author{
Murat Kanlioz $^{1}$, Turgay Karatas ${ }^{2}$ \\ 1. General Surgery, Beylikdüzü Kolan Hospital, Istanbul, TUR 2. Anatomy, Inönü University, Malatya, TUR
}

Corresponding author: Murat Kanlioz, muratkanlioz@gmail.com

\section{Abstract \\ Introduction}

Very different results have been reported regarding the relationship between bilirubin and perforated appendicitis. We observed this relationship with our own studies.

\section{Methods}

The patients, who underwent appendectomy, were retrospectively categorized as perforated and nonperforated based on their files. Those with a total bilirubin (TB) $1.20 \mathrm{mg} / \mathrm{dL}$ or less were considered normal whereas those with a $1.21 \mathrm{mg} / \mathrm{dL}$ or higher were considered having a high. Those with a direct bilirubin (DB) $0.50 \mathrm{mg} / \mathrm{dL}$ or less were considered normal whereas those with a $0.51 \mathrm{mg} / \mathrm{dL}$ or higher were considered having a high. The patients were assessed under two groups. Perforated appendicitis (PA) and nonperforated appendicitis (NPA) were analyzed according to the TB in Group 1 and the DB in Group 2.

\section{Results}

Group 1 included 269 patients whose TB were measured. Of those, 218 had NPA and 51 had PA. The rate of patients with high TB among the patients with PA was 1.37 times higher than those with NPA ( $\left.p^{<} 0.01\right)$. Group 2 included 258 patients whose DB values were measured. Of those, 208 had NPA and 50 had PA. The rate of patients with high TB among the patients with PA was 1.71 times higher than those with NPA ( $p^{\text {c }}$ $0.001)$.

\section{Conclusion}

In the diagnosis of $\mathrm{PA}$, both $\mathrm{TB}$ and $\mathrm{DB}$ show low diagnostic values. In the diagnosis, they can only be considered as a supportive factor to other parameters. However, in the case of a differential diagnosis, we recommend using DB since it has a higher sensitivity and specificity.

Received 11/28/2019 Review began 12/04/2019 Review ended 12/05/2019 Published 12/08/2019

๑) Copyright 2019 Kanlioz et al. This is an open access article distributed under the terms of the Creative Commons Attribution License CC-BY 3.0., which permits unrestricted use, distribution, and reproduction in any medium, provided the original author and source are credited.
Categories: Emergency Medicine, General Surgery

Keywords: perforated appendicitis, total bilirubin, direct bilirubin, acute appendicitis, acute appendicitis

\section{Introduction}

Acute appendicitis (AP) is the most common non-traumatic surgery emergency [1]. It is important to determine whether the AP is perforated or not at the stage of diagnosis to minimize complications [2]. The process in AP begins with the obstruction of the appendix lumen. Lymphoid activity is important in lumen blockage. AP is most common in ages 20-30, and it is known that lymphoid activity is high in this period [3]. Other factors in the obstruction of the appendix lumen include fecaloma, parasitosis, foreign bodies and rarely tumoral formations. As the drainage of the mucus produced from the mucosa cannot occur due to the blockage of the lumen, the pressure inside the lumen will increase. As the pressure increases, venous and arterial blood flow is disrupted, microbial colonization increases and pain is added to the table, respectively [4]. Perforation may be seen in the progressive process. This is attributed to the increase of Kupffer cell function and hepatocyte injury as a result of excessive bacterial and toxin load from the liver via portal venous system, as well as increased serum bilirubin and suppression of hepatic bilirubin destruction functions as a result of increased acute phase reactants such as IL-6 and TNF [5]. Anamnesis is important in the diagnosis of AP. The patient applies with anorexia, nausea, abdominal pain and fever [3]. In the examination, defense and rebound tenderness are typical in the lower right quadrant of the abdomen [4]. Some maneuver and findings are helpful in the diagnosis (Rovsing's sign, etc.). Leukocytosis, increased neutrophil rate, increased C-reactive protein (CRP), increased bilirubin, procalcitonin and IL-6 are helpful in diagnosis [1,6-8]. Ultrasonography, computed tomography and magnetic resonance imaging are valuable in diagnosis [2,9]. It is important to observe a curve of the bowel with edema in the right lower quadrant in Xray. Some scoring tests (Alvarado, Heidelberg) and laparoscopy are used in the diagnosis [10-12]. Primary treatment in AP is surgery. However, there are also studies evaluating medical treatment as an option [13]. In the surgical treatment, laparoscopic and open surgery are performed to investigate the importance of total bilirubin (TB) and direct bilirubin (DB) levels in the diagnosis of perforated appendicitis (PA) [10]. 


\section{Cureus}

\section{Materials And Methods}

The files of the 269 patients, who underwent appendectomy, were examined retrospectively. Patients who were reported as acute appendicitis as a result of post-operative pathology were included in the study. The patients with complete results of pre-operative serum bilirubin and post-operative pathology were included in the study. The pre-operative serum TB and DB levels of the patients were recorded. Those with a TB 1.20 $\mathrm{mg} / \mathrm{dL}$ or less were considered normal whereas those with a $1.21 \mathrm{mg} / \mathrm{dL}$ or higher were considered having a high. Those with a DB $0.50 \mathrm{mg} / \mathrm{dL}$ or less were considered normal whereas those with a $0.51 \mathrm{mg} / \mathrm{dL}$ or higher were considered having a high. The patients were categorized as "perforated appendicitis (PA)" and "nonperforated appendicitis (NPA)" based on their post-operative pathologic results. The patients were assessed under two groups. It was analyzed whether there is a difference between the PA and NPA according to the TB in Group 1 and DB in Group 2. SPSS statistical software was used. The between-groups distribution was evaluated using Kolmogorov-Smirnov test. The results were analyzed using "Pearson Chi-Square Test". p 0.05 was considered significant.

\section{Results}

In Group 1, the pre-operative TB in 269 patients were measured. The patients, of whom 148 (55\%) were male and 121 (45\%) were female, had a mean age of 28 years. Of those patients, 218 (81\%) had NPA and 51 (19\%) had PA. TB was high in 31 (14\%) of 218 patients with NPA, and in 10 (20\%) of 51 patients with PA (Table 1$)$. TB was 1.37 times higher in the patients with PA than those with NPA ( $\left.\mathrm{p}^{<} 0.01\right)$. In patients with PA, the TB showed a sensitivity of $20 \%$, a specificity of $14 \%$, a positive predictive value of $24 \%$, and a negative predictive value of $18 \%$.

\begin{tabular}{|c|c|c|c|}
\hline & \multicolumn{2}{|c|}{ Total Bilirubin } & \multirow{2}{*}{ Tota } \\
\hline & Normal (n) & High (n) & \\
\hline Non-perforated & $187(86 \%)$ & $31(14 \%)$ & 218 \\
\hline Perforated & 41 (80\%) & $10(20 \%)$ & 51 \\
\hline TOTAL & $28(85 \%)$ & $41(15 \%)$ & 9 \\
\hline
\end{tabular}

\section{TABLE 1: Total bilirubin levels in appendectomies}

In Group 2, DB in 258 patients were measured in the pre-operative period. The mean age of the patients, of whom 144 (56\%) were male and 114 (44\%) were female, was 28.7 years. Of those patients, 208 (81\%) had NPA and 50 (19\%) had PA. DB was high in 17 (8.17\%) of 208 patients with NPA, and in seven (14\%) of 50 patients with PA (Table 2). DB was 1.71 times higher in the patients with PA than those with NPA ( $\left.\mathrm{p}^{<} 0.001\right)$. DB showed a sensitivity of $14 \%$, a specificity of $8 \%$, a positive predictive value of $29 \%$, and a negative predictive value of $18 \%$.

\begin{tabular}{|c|c|c|c|}
\hline & \multicolumn{2}{|c|}{ Direct Bilirubin } & \multirow{2}{*}{ Total } \\
\hline & Normal (n) & High (n) & \\
\hline Non-perforated & 191 (92\%) & 17 (8\%) & 208 \\
\hline Perforated & $43(86 \%)$ & 7 (14\%) & 50 \\
\hline TOTAL & 234 (85\%) & 24 (15\%) & 258 \\
\hline
\end{tabular}

TABLE 2: Direct bilirubin levels in appendectomies

In the analysis performed using Kolmogorov-Smirnov test, between-groups distribution was considered normal.

\section{Discussion}

There are many methods used in the diagnosis of acute appendicitis and while determining whether it is perforated or not following the diagnosis. One of those methods includes measuring the serum bilirubin level. This study aims to reveal the correlation between the bilirubin level and the appendicitis. The methods 
used during the diagnoses are aimed at ensuring an early diagnosis and recognizing the perforation, if any. Because, a perforation in appendicitis leads to a significant increase in morbidity and mortality. The aim is to perform the surgery before the appendicitis gets perforated. Besides, if diagnosed with PA, the patient should be given priority in the treatment and the processes should be accelerated. In both study groups, the perforation rate was $19 \%$. The perforation rates in appendectomies performed were reported to be $20.2 \%$ in the study carried out by Barreto et al., $15.7 \%$ in the study of Siddique et al., and $24 \%$ in the study of Adams and Jaunoo $[7,8,14]$. In our study, there was $15 \%$ hyperbilirubinemia in Group 1. In the study of Estrada et al., 59 (38\%) of the 157 patients who underwent appendectomy had hyperbilirubinemia [15]. Bonadio et al. reported that TB was high in $22 \%$ of the NPA [16]. In our study, this rate was $14.22 \%$ in patients with NPA in Group 1. The rates of high TB in PA were reported to be $36 \%$ by Bonadio et al. and $48 \%$ by Müller et al., whereas Saxena et al. reported that this was $100 \%$ in their study [16-18]. However, we found in our study that the total bilirubin level was high in $20 \%$ of PA in Group 1 . We believe that especially the rate reported by Saxena et al. is highly disputable. Alanis-Rivera et al. reported in their study that the rate of TB in patients with PA was 17 times higher than in those with NPA [19]. This rate was reported to be five times higher by Eren et al. [20]. In the 557-patient series of Adams and Jaunoo, no significant difference was found between the perforated and non-perforated group in terms of bilirubin values [14]. In Group 1, we found that the TB in patients with PA was 1.37 times higher than those with NPA. The fact that such differing results have been obtained so far requires undertaking more detailed studies.

Eren et al. reported that the DB was 36 times higher in patients with PA than in those with NPA [20]. In another study, however, Nevler et al. set forth that they found a significant correlation between PA and the DB ( $\left.p^{<} 0.001\right)$ [21]. In Group 2, we found that DB in patients with PA was 1.71 times higher than in those with NPA.

Among the appendectomies, our results in terms of PA are at an average level according to the literature, however it is clear that these rates need to be further reduced. In our age, the fact that one out of every five cases is perforated and that the perforation leads to severe mortality and morbidity rates are unacceptable. Many studies have so far reported that there is a correlation between PA and bilirubin, however there are serious differences between the results obtained. Whilst some studies show a strong correlation in between, our studies do not support such strong correlation. When we examine the level of bilirubin in appendicitis in terms of sensitivity, specificity, and predictivity, we see, on the basis of our findings, that these constitute a supportive factor for the diagnosis together with several parameters.

\section{Conclusions}

In PA, we can use the bilirubin levels for the purpose of differential diagnosis. However, we should note at this point that, if the bilirubin level is high, this is of significance in terms of diagnosis, however a non-high bilirubin level should not mislead us that there is no perforation. Given its sensitivity and specificity, we can state that $\mathrm{DB}$ has a higher diagnostic value than $\mathrm{TB}$.

\section{Additional Information \\ Disclosures}

Human subjects: All authors have confirmed that this study did not involve human participants or tissue. Animal subjects: All authors have confirmed that this study did not involve animal subjects or tissue. Conflicts of interest: In compliance with the ICMJE uniform disclosure form, all authors declare the following: Payment/services info: All authors have declared that no financial support was received from any organization for the submitted work. Financial relationships: All authors have declared that they have no financial relationships at present or within the previous three years with any organizations that might have an interest in the submitted work. Other relationships: All authors have declared that there are no other relationships or activities that could appear to have influenced the submitted work.

\section{References}

1. Acharya A, Markar SR, Ni M, Hanna GB: Biomarkers of acute appendicitis: systematic review and costbenefit trade-off analysis. Surg Endosc. 2017, 31:1022-1031. 10.1007/s00464-016-5109-1

2. Siddiqui AH, Afzal S: Perforated appendicitis: accuracy of CT diagnosis and correlation of CT findings with the length of hospital stay. J Coll Physicians Surg Pak. 2007, 17:721-725. 12.2007/JCPSP.721725

3. Prystowsky JB, Pugh CM, Nagle AP: Appendicitis. Curr Probl Surg. 2005, 42:694-742. 10.1067/j.cpsurg.2005.07.005

4. Coskun T, Kaya Y: Acute appendicitis. Basic Surgery. Sayek I (ed): Gunes Bookstore, Ankara; 2013. 2:13421350.

5. Chaudhary P, Kumar A, Saxena N, Biswal UC: Hyperbilirubinemia as a predictor of gangrenous/perforated appendicitis: a prospective study. Ann Gastroenterol J. 2013, 26:325-331.

6. Kanlioz M, Ekici U, Tatli F, Karatas T, Inan T: Is there any relationship between complicated appendicitis and leucocyte counts. J Turgut Ozal Med Center. 2016, 23:152-155. 10.5455/jtomc.2016.02.027

7. Barreto SG, Travers E, Thomas T, Mackillop C, Tiong L, Lorimer M, Williams R: Acute perforated appendicitis: an analysis of risk factors to guide surgical decision making. India J Med Sci. 2010, 64:58-65. 10.4103/0019-5359.94401

8. Siddique K, Baruah P, Bhandari S, Mirza S, Harinath G: Diagnostic accuracy of white cell count and C- 
reactive protein for assessing the severity of paediatric appendicitis. JRSM Short Rep. 2011, 2:1-6. 10.1258/shorts.2011.011025

9. Tatli F, Ekici U, Kanlioz M, Gozeneli O, Uzunkoy A, Yucel Y, Dirican A: Ultrasonography in diagnosis of acute appendicitis. Ann Ital Chir. 2016, 87:152-154.

10. McGreevy JM, Finlayson SR, Alvarado R, Laycock WS, Birkmeyer CM, Birkmeyer JD: Laparoscopy may be lowering the threshold to operate on patients with suspected appendicitis. Surg Endosc. 2002, 16:10461049. 10.1007/s00464-001-8332-2

11. Boettcher M, Günther P, Breil T: The Heidelberg appendicitis score predicts perforated appendicitis in children. Clin Pediatr (Phila). 2017, 56:1115-1119. 10.1177/0009922816678976

12. Tatli F, Ekici U, Kanlioz M, Gözeneli O, Uzunköy A, Yücel Y, Dirican A: Efficiency of Alvarado score in diagnosis of acute appendicitis. J Turgut Ozal Med Cent. 2016, 23:26-28. 10.5455/jtomc.2015.11-030

13. Salminen P, Paajanen H, Rautio T, et al.: Antibiotic therapy vs appendectomy for treatment of uncomplicated acute appendicitis: the APPAC randomized clinical trial. JAMA. 2015, 313:2340-2348. 10.1001/jama.2015.6154

14. Adams HL, Jaunoo SS: Hyperbilirubinaemia in appendicitis: the diagnostic value for prediction of appendicitis and appendiceal perforation. Eur J Trauma Emerg Surg. 2016, 42:249-252. 10.1007/s00068-0150540-X

15. Estrada JJ, Petrosyan M, Barnhart J, Tao M, Sohn H, Towfigh S, Mason RJ: Hyperbilirubinemia in appendicitis: a new predictor of perforation. J Gastrointest Surg. 2007, 11:714-718. 10.1007/s11605-0070156-5

16. Bonadio W, Bruno S, Attaway D, Dharmar L, Tam D, Homel P: Lack of utility of measuring serum bilirubin concentration in distinguishing perforation status of pediatric appendicitis. Am J Emerg Med. 2017, 35:885888. 10.1016/j.ajem.2017.01.056

17. Muller S, Falch C, Axt S, Wilhelm P, Hein D, Königsrainer A, Kirschniak A: Diagnostic accuracy of hyperbilirubinaemia in anticipating appendicitis and its severity. Emerg Med J. 2015, 32:698-702. 10.1136/emermed-2013-203349

18. Saxena D, Tandon M, Şah Y, Gedam BS: Hyperbilirubinemia as a diagnostic tool for the prediction of appendicular perforation: a prospective study. Euroasian J Hepato-Gastroenterol. 2015, 5:87-89. 10.5005/jpjournals-10018-1141

19. Alanis-Rivera B, Zúñiga-Vázquez LA, Silva-Escamilla MC: Hyperbilirrubinemia as a predictive factor of perforated appendicitis. (Article in Spanish). Rev Med Inst Mex Seguro Soc. 2016, 54:552-561.

20. Eren T, Tombalak E, Ozemir IA, Leblebici M, Ziyade S, Ekinci O, Alimoglu O: Hyperbilirubinemia as a predictive factor in acute appendicitis. Eur J Trauma Emerg Surg. 2016, 42:471-476. 10.1007/s00068-0150562-4

21. Nevler A, Berger Y, Rabinovitz A, Zmora O, Shabtai M, Rosin D, Gutman M: Diagnostic value of serum bilirubin and liver enzyme levels in acute appendicitis. Isr Med Assoc J. 2018, 20:176-181. 